ARTIKEL PENELITIAN

\title{
HUBUNGAN STATUS SOSIAL EKONOMI ORANG TUA DENGAN KARIES PADA GIGI SULUNG ANAK UMUR 4 DAN 5 TAHUN
}

\author{
Susi $^{1}$, Hafni Bachtiar ${ }^{2}$, Ummul Azmi $^{3}$ \\ 1. Fakultas Kedokteran Gigi Universitas Andalas \\ 2. Fakultas Kedokteran Universitas Andalas \\ 3. Mahasiswa Fakultas Kedokteran Gigi Universitas Andalas \\ email : susiabidin@gmail.com
}

\begin{abstract}
Abstrak
Karies merupakan masalah utama di rongga mulut anak. Kerusakan gigi sulung lebih cepat menyebar, meluas dan lebih parah dari pada gigi permanen. Karies lebih banyak ditemukan pada orang dengan status sosial ekonomi rendah. Tujuan dari penelitian ini adalah untuk mengetahui hubungan status sosial ekonomi dengan kejadian karies pada gigi sulung anak usia 4 dan 5 tahun pada murid TK Adzkia II, TK Lillah, dan TK Mutiara Ananda di Kota Padang.

Penelitian ini bersifat observasi analitik menggunakan metode cross sectional. Populasi penelitian ini adalah murid TK Adzkia II, TK Lillah, dan TK Mutiara Ananda yang berumur 4-5 tahun atau murid lokal A yang berjumlah sebanyak 59 orang, sampel yang diteliti 57 orang. Metode pengambilan data primer yaitu dengan melakukan wawancara dengan orang tua dan pemeriksaan status karies responden.

Hasil penelitian menunjukkan status sosial ekonomi orang tua dari responden 75,4\% tidak miskin dan status karies responden 50,9\% baik. Dari responden yang tidak miskin, 46,5\% memiliki status karies yang buruk, 53,5\% memiliki status karies yang baik. Hasil uji statistik diperoleh tidak ada hubungan yang bermakna dari proporsi status karies responden dengan pendapatan orang tua responden.

Dari penelitian ini dapat disimpulkan bahwa responden dengan status sosial ekonomi tidak miskin dan status karies baik lebih dominan. Disarankan kepada sekolah agar memberikan pengetahuan tentang kesehatan gigi dan mulut secara rutin kepada murid - murid dan bagi orang tua lebih memperhatikan jajanan yang dikonsumsi oleh anaknya.
\end{abstract}

Kata Kunci : karies, status sosial ekonomi

\section{Abstract}

Caries is a major issue in the oral cavity of children. Damage spreading deciduous teeth faster, more widespread and severe than in permanent teeth. Caries are more common in people with low socioeconomic status. The purpose of this study was to determine the relationship of socioeconomic parents status with the incidence of caries in primary teeth of kindergarten students age 4 and 5 years in Adzkia II, Lillah, and Mutiara Ananda in Padang. 
This observational study using cross sectional analytic. The study population was kindergarten students aged 4-5 years Adzkia II, Lillah, and Mutiara Ananda or A local student who numbered as many as 59 people, the studied sample of 57 people. Primary data collection method is to conduct interviews with parents and the examination of dental caries status of respondents.

Research shows parental socioeconomic status of respondents $75.4 \%$ were not poor and caries status of respondents $50.9 \%$ good. Of the respondents who are not poor, $46.5 \%$ had caries status poor, $53.5 \%$ had a good caries status. The results of statistical tests obtained no significant association of the proportion of caries status of respondents with incomes of respondents.

From this study it can be concluded that the respondents with the non-poor socioeconomic status and caries status either more dominant. Recommended to the schools to provide knowledge about oral health on a regular basis to students - for students and parents pay more attention to snacks consumed by children.

Key word : caries, socioeconomic status. 


\section{PENDAHULUAN}

Pembangunan di bidang kesehatan bertujuan untuk meningkatkan derajat kesehatan masyarakat agar tingkat kesehatan masyarakat menjadi lebih baik. Pembangunan di bidang kesehatan gigi merupakan bagian integral pembangunan kesehatan nasional. Dalam melaksanakan pembangunan kesehatan, pembangunan dibidang kesehatan gigi tidak boleh ditinggalkan, demikian juga sebaliknya. Pelaksanakan pembangunan dibidang kesehatan gigi, tidak terlepas dari kerangka yang lebih luas, yaitu pembangunan di bidang kesehatan umumnya. ${ }^{(1)}$

Status atau derajat kesehatan masyarakat ditentukan oleh berbagai faktor seperti penduduk, lingkungan, perilaku masyarakat dan pelayanan kesehatan. Dalam mengatasi masalah kesehatan faktor tersebut perlu mendapat perhatian serta penanganan sebagai satu kesatuan. Untuk menunjang upaya kesehatan agar mencapai derajat kesehatan optimal (hidup sehat), upaya di bidang kesehatan gigi juga perlu mendapatkan perhatian. ${ }^{(2)}$

Kesehatan gigi dan mulut merupakan bagian dari kesehatan keseluruhan. Masalah utama dalam kesehatan gigi dan mulut anak-anak adalah karies. Pada tahun 2000 United States Surgeon General melaporkan bahwa karies merupakan penyakit infeksi yang paling banyak diderita anak-anak. Karies lebih tinggi 5 kali diderita anak-anak dibandingkan penyakit asthma dan 7 kali lebih banyak diderita anak-anak dibandingkan dengan penyakit demam. ${ }^{(3)}$

Kesehatan Gigi dan Mulut anak di Indonesia masih sangat memprihatinkan sehingga perlu mendapatkan perhatian yang serius dari tenaga kesehatan. Masalah utama yang terjadi dalam rongga mulut adalah karies gigi. Karies gigi adalah penyakit dengan penyebab multifaktor. Prevalensi dan insiden karies gigi dalam suatu populasi dipengaruhi oleh sejumlah faktor resiko seperti jenis kelamin, usia, status sosial ekonomi, pola diet dan kebiasaan menjaga kebersihan gigi dan mulut. ${ }^{(4)}$

Baik gigi sulung maupun gigi permanen, mempunyai resiko terkena karies, namun proses kerusakan gigi sulung lebih cepat menyebar, meluas dan lebih parah dari gigi permanen. Hal tersebut terjadi karena : perbedaan struktur email gigi dimana gigi sulung mempunyai struktur email yang kurang padat dan lebih tipis, morfologi lebih tidak beraturan, dan kontak antara gigi merupakan kontak bidang pada gigi sulung. ${ }^{(1)}$

Untuk tahun 2010, WHO (World Health Organization) telah menargetkan indeks DMFT (Decayed, Missing, Filled-Tooth) adalah 1,0 sedangkan di Negara berkembang menetapkan indeks karies adalah 1,2. Berbagai indikator telah ditentukan WHO, antara lain pada anak umur 5 tahun $90 \%$ harus bebas karies, anak umur 12 tahun mempunyai indeks DMF-T sebesar 1, penduduk umur 18 tahun tidak ada gigi yang dicabut (komponen $\mathrm{M}=0$ ), dan penduduk umur 35-44 tahun memiliki minimal 20 gigi berfungsi sebesar $90 \%$. $^{(5)}$

Di dunia, karies gigi merupakan salah satu masalah yang paling penting dan merupakan salah satu faktor yang berkontribusi terhadap kesehatan manusia secara keseluruhan. Di seluruh dunia rata-rata $90 \%$ anak sekolah dan orang dewasa memiliki pengalaman karies. Karies merupakan penyakit yang paling umum di negara-negara Asia dan Amerika Latin. Di Amerika Serikat, karies gigi merupakan penyakit kronis yang paling umum diderita anak, setidaknya lima kali lebih umum dari 
asma, dan merupakan penyebab patologis utama kehilangan gigi pada anak. $^{(6)}$ Penyakit gigi dan mulut merupakan penyakit tertinggi keenam yang dikeluhkan masyarakat Indonesia dan menempati peringkat keempat dalam penyakit termahal dalam pengobatan. Di Negara-negara maju prevalensi karies gigi terus menurun, sedangkan di negara - negara berkembang seperti Indonesia cenderung meningkat. Berdasarkan data dari Riskesdas, prevalensi karies pada anak umur 1-4 tahun di Indonesia sebesar 6,9\%, sedangkan pada anak umur 5-9 tahun sebesar 21,6\%. ${ }^{(5)}$

Di Provinsi Sumatera Barat penduduk dengan umur 1-4 tahun yang mempunyai masalah dengan kesehatan gigi dan mulut sebesar 5,2 \% dan pada usia 5-9 tahun sebesar $21,1 \%$, dari angka ini terlihat dengan meningkatnya umur meningkat juga masalah kesehatan gigi dan mulutnya, terutama karies. Di kota Padang, penyakit gigi dan mulut masih menjadi penyakit dengan peringkat pertama diantara sepuluh penyakit terbanyak. Dengan tingginya angka prevalensi karies pada anak sekolah TK (Taman Kanak-kanak) di kota Padang tahun 2009 sebesar $52 \%$. $^{(5)}$

Banyak penelitian menunjukkan bahwa prevalensi karies lebih tinggi pada anak yang berstatus sosial ekonomi rendah. $^{(6)}$ Penelitian yang pernah dilakukan di Chidambaram (India), meneliti tentang hubungan status sosial ekonomi dengan prevalensi karies gigi pada anak-anak sekolah usia antara 5-15 tahun, didapatkan hasil bahwa persentase karies yang dialami oleh anak-anak tersebut tergolong tinggi. Dalam penelitian tersebut $80,4 \%$ siswa adalah kelompok sosial ekonomi rendah. $^{(7)}$
Jurnal dari Indian Soc Pedod Prev Dent, melaporkan bahwa berdasarkan penelitian yang di lakukan di Kota Mangalore, pada anak usia 6 tahun yang prevalensi kariesnya tinggi terdapat pada anak dengan latar belakang status sosial ekonomi rendah. ${ }^{(8)}$ Di Burkina Faso, Afrika, juga pernah dilakukan penelitan pada umur $6,12,18$, dan 3544 tahun, dan didapatkan hasil pada anak usia 6 tahun menunjukkan angka prevalensi karies sebesar $38 \% .^{(9)}$

Azwindar pada tahun 2009 melakukan penelitian dengan tema yang sama juga pernah dilakukan di Kelurahan Barombong Kecamatan Tamalate Makassar. Penelitian tersebut melihat hubungan tingkat sosial ekonomi dengan status karies masyarakat di kelurahan tersebut, didapatkan hasil tingginya status karies pada masyarakat dengan status ekonomi rendah. ${ }^{(10)}$

Berdasarkan uraian-uraian di ataslah penulis tertarik untuk meneliti hubungan status sosial ekonomi dengan status karies pada anak TK. Dalam penelitian ini TK yang akan dipilih yaitu TK Adzkia II, TK Lillah, dan TK Mutiara Ananda yang terletak pada satu kelurahan, yakni kelurahan Bungo Pasang, kecamatan Koto Tangah, Padang, dimana TK tersebut dipilih oleh peneliti berdasarkan SPP (Sumbangan Pembangunan Pendidikan) yang mana TK Adzkia II memiliki SPP paling tinggi, kemudian TK Lillah dan yang paling rendah yaitu TK Mutiara Ananda.

\section{METODE PENELITIAN}

Jenis penelitian yang akan digunakan dalam tugas akhir ini yaitu penelitian observasional analitik dengan metode cross sectional yaitu variable independen atau faktor resiko dan tergantung (efek) dinilai secara simutan 
pada satu saat, peneliti melakukan pengamatan langsung kepada responden. $^{(11)}$

Sampel dalam penelitian ini adalah murid TK Adzkia II, TK Lillah, dan TK Mutiara Ananda yang berada di tempat pada saat pelaksanaan penelitian ini. keterangan:

Kategori miskin dan tidak miskin $\mathrm{N}=$ besar populasi

menggunakan indikator dari Badan $\mathrm{n}=$ besar sampel

Pusat Statistik berdasarkan pendapatan $\mathrm{d}=$ tingkat kepercayaan yang perkapita sebulan sebesar Rp. 243.729,- diinginkan

. Pengambilan sampel ini menggunakan metode pemilihan sampel menurut Notoatmodjo $^{(12)}$ adalah :

HASIL

Tabel 1 Karakteristik Responden Berdasarkan Umur

\begin{tabular}{ccccccccc}
\hline \multirow{2}{*}{ Umur } & \multicolumn{2}{c}{$\begin{array}{c}\text { TK Adzkia } \\
\text { II }\end{array}$} & \multicolumn{2}{c}{ TK Lillah } & \multicolumn{2}{c}{$\begin{array}{c}\text { TK Mutiara } \\
\text { Ananda }\end{array}$} & \multicolumn{2}{c}{ Jumlah } \\
\cline { 2 - 9 } & f & $\%$ & f & $\%$ & f & $\%$ & f & $\%$ \\
\hline 4 & 1 & 4,0 & 3 & 13,6 & - & - & 4 & 7 \\
5 & 8 & 32,0 & 19 & 86,4 & 7 & 70 & 34 & 59,7 \\
6 & 16 & 64,0 & - & - & 3 & 30 & 19 & 33,3 \\
\hline Jumlah & 25 & 100 & 22 & 100 & 10 & 100 & 57 & 100 \\
\hline
\end{tabular}

Tabel 2. Karakteristik Responden Berdasarkan Jenis Kelamin

\begin{tabular}{ccccccccc}
\hline \multirow{2}{*}{$\begin{array}{c}\text { Jenis } \\
\text { kelamin }\end{array}$} & \multicolumn{2}{c}{$\begin{array}{c}\text { TK Adzkia } \\
\text { II }\end{array}$} & \multicolumn{2}{c}{ TK Lillah } & \multicolumn{2}{c}{$\begin{array}{c}\text { TKMutiara } \\
\text { Ananda }\end{array}$} & Jumlah \\
\cline { 2 - 9 } & f & $\%$ & f & $\%$ & f & $\%$ & f & $\%$ \\
\hline Laki-lakj & 11 & 44,0 & 12 & 54,5 & 2 & 20,0 & 25 & 43,9 \\
Perempuan & 14 & 56,0 & 10 & 45,5 & 8 & 80,0 & 32 & 56,1 \\
\hline Jumlah & 25 & 100 & 22 & 100 & 10 & 100 & 57 & 100 \\
\hline
\end{tabular}

Tabel 3. Karakteristik Responden Berdasarkan Pendidikan Orang tua

\begin{tabular}{|c|c|c|c|c|c|c|c|c|}
\hline \multirow{2}{*}{ Pendidikan } & \multicolumn{2}{|c|}{ TK Adzkia II } & \multicolumn{2}{|c|}{ TK Lillah } & \multicolumn{2}{|c|}{$\begin{array}{c}\text { TK Mutiara } \\
\text { Ananda }\end{array}$} & \multicolumn{2}{|c|}{ Jumlah } \\
\hline & $\mathrm{f}$ & $\%$ & f & $\%$ & f & $\%$ & f & $\%$ \\
\hline $\begin{array}{c}\text { Ayah } \\
\text { SMA } \\
\text { Sarjana }\end{array}$ & $\begin{array}{c}5 \\
20 \\
\end{array}$ & $\begin{array}{l}20 \\
80 \\
\end{array}$ & $\begin{array}{c}8 \\
14 \\
\end{array}$ & $\begin{array}{l}36 \\
64 \\
\end{array}$ & $\begin{array}{l}5 \\
5 \\
\end{array}$ & $\begin{array}{l}50 \\
50 \\
\end{array}$ & $\begin{array}{l}18 \\
39 \\
\end{array}$ & $\begin{array}{l}31,6 \\
68,4 \\
\end{array}$ \\
\hline $\begin{array}{c}\text { Ibu } \\
\text { SMA } \\
\text { Sariana }\end{array}$ & $\begin{array}{c}3 \\
22\end{array}$ & $\begin{array}{l}12 \\
88\end{array}$ & $\begin{array}{c}5 \\
17\end{array}$ & $\begin{array}{l}23 \\
77\end{array}$ & $\begin{array}{l}4 \\
6\end{array}$ & $\begin{array}{l}40 \\
60\end{array}$ & $\begin{array}{l}12 \\
45\end{array}$ & $\begin{array}{l}20,0 \\
80,0\end{array}$ \\
\hline
\end{tabular}


Tabel 4. Karakteristik Responden Berdasarkan Pekerjaan Orang Tua

\begin{tabular}{|c|c|c|c|c|c|c|c|c|}
\hline \multirow{2}{*}{ Pekerjan } & \multicolumn{2}{|c|}{ TK Adzkia II } & \multicolumn{2}{|c|}{ TK Lillah } & \multicolumn{2}{|c|}{$\begin{array}{l}\text { TKMutiara } \\
\text { Ananda }\end{array}$} & \multicolumn{2}{|c|}{ Jumlah } \\
\hline & f & $\%$ & f & $\%$ & $\mathrm{f}$ & $\%$ & $f$ & $\%$ \\
\hline $\begin{array}{l}\text { Ayah } \\
\text { PNS } \\
\text { Swyasta }\end{array}$ & $\begin{array}{l}13 \\
12\end{array}$ & $\begin{array}{l}52 \\
48\end{array}$ & $\begin{array}{c}7 \\
15\end{array}$ & $\begin{array}{l}31,8 \\
68,2\end{array}$ & $\begin{array}{l}2 \\
8\end{array}$ & $\begin{array}{l}20 \\
80\end{array}$ & $\begin{array}{l}22 \\
35\end{array}$ & $\begin{array}{l}38,5 \\
61,5\end{array}$ \\
\hline $\begin{array}{c}\text { Ibu } \\
\text { Bekerja } \\
\text { Tidak Bekeria }\end{array}$ & $\begin{array}{l}15 \\
10\end{array}$ & $\begin{array}{l}60 \\
40\end{array}$ & $\begin{array}{l}11 \\
11\end{array}$ & $\begin{array}{l}23 \\
77\end{array}$ & $\begin{array}{l}4 \\
6\end{array}$ & $\begin{array}{l}40 \\
60\end{array}$ & $\begin{array}{l}30 \\
27\end{array}$ & $\begin{array}{l}52,6 \\
47,4\end{array}$ \\
\hline
\end{tabular}

Tabel 5 Distribusi Pendapatan Orang Tua Responden

\begin{tabular}{ccc}
\hline Status Sosial Ekonomi & $\mathrm{f}$ & $\%$ \\
\hline Miskin & 14 & 24,6 \\
Tidak Miskin & 43 & 75,4 \\
\hline Jumlah & 57 & 100,0 \\
\hline
\end{tabular}

Tabel 6 Distribusi Status Karies Responden

\begin{tabular}{ccc}
\hline Status Karies & $\mathrm{f}$ & $\%$ \\
\hline Buruk & 28 & 49,1 \\
Baik & 29 & 50,9 \\
\hline Jumlah & 57 & 100,0 \\
\hline
\end{tabular}

Tabel 7. Hubungan Status Sosial Ekonomi Orang Tua Dan Status Karies

\begin{tabular}{cccccccc}
\hline & \multicolumn{4}{c}{ Status Karies } & & & \\
\cline { 2 - 6 } Status Sosial & \multicolumn{3}{c}{ Buruk } & \multicolumn{3}{c}{ Baik } & \multicolumn{2}{c}{ Jumlah } & \multirow{2}{*}{$\mathrm{P}$} \\
\cline { 2 - 6 } Ekonomi & $\mathrm{f}$ & $\%$ & $\mathrm{f}$ & $\%$ & $\mathrm{f}$ & $\%$ & \\
\hline Miskin & 8 & 57,1 & 6 & 42,9 & 14 & 100 & \\
Tidak Miskin & 20 & 46,5 & 23 & 53,5 & 43 & 100 & \\
& & & & & & & 0,490 \\
\hline Jumlah & 28 & 49,1 & 29 & 50,9 & 57 & 100 & \\
\hline
\end{tabular}




\section{Tabel 8. Hubungan Pendidikan Orang Tua Responden dan Status Karies}

\begin{tabular}{cccccccc}
\hline Pendidikan Orang Tua & & \multicolumn{5}{c}{ Karies } & \multirow{2}{*}{ P } \\
\cline { 4 - 7 } & & & \multicolumn{3}{c}{ Baik } & \multicolumn{3}{c}{ Buruk } & \\
\hline Ayah & $\mathrm{f}$ & $\%$ & $\mathrm{f}$ & $\%$ & $\mathrm{f}$ & $\%$ & \\
Sarjana & 43 & 75,4 & 23 & 53,5 & 20 & 46,5 & \multirow{2}{*}{0,490} \\
Tidak Sarjana & 14 & 24,6 & 6 & 42,9 & 8 & 57,1 & \\
\hline Ibu & $\mathrm{f}$ & $\%$ & $\mathrm{f}$ & $\%$ & $\mathrm{f}$ & $\%$ & \\
Sarjana & 45 & 21,1 & 24 & 53,3 & 21 & 46,7 & \multirow{2}{*}{0,146} \\
Tidak Sarjana & 12 & 78,9 & 5 & 41,7 & 7 & 58,3 & \\
\hline
\end{tabular}

Tabel 9. Hubungan Pekerjaan Orang Tua Responden dengan Status Karies

\begin{tabular}{|c|c|c|c|c|c|c|c|}
\hline \multirow{2}{*}{\multicolumn{3}{|c|}{ Pekerjaan Orang Tua }} & \multicolumn{4}{|c|}{ Karies } & \multirow{3}{*}{$P$} \\
\hline & & & \multicolumn{2}{|c|}{ Baik } & \multicolumn{2}{|c|}{ Buruk } & \\
\hline Ayah & $f$ & $\%$ & $\mathrm{f}$ & $\%$ & $\mathrm{f}$ & $\%$ & \\
\hline PNS & 28 & 49,1 & 17 & 58,6 & 11 & 39,3 & 0,144 \\
\hline Non PNS & 29 & 50,9 & 12 & 41,4 & 17 & 60,7 & \\
\hline Ibu & $\mathrm{f}$ & $\%$ & $f$ & $\%$ & f & $\%$ & \\
\hline Bekeria & 30 & 52,6 & 18 & 60 & 12 & 40 & 0,146 \\
\hline Tidak Bekeria & 27 & 47,4 & 11 & 40,7 & 16 & 59,3 & \\
\hline
\end{tabular}

\section{PEMBAHASAN}

Dari hasil penelitian diketahui karakteristik responden yang berumur 5 tahun sebanyak 59,7\%, berjenis kelamin perempuan sebanyak $56,1 \%$. Prevalensi karies meningkat dengan bertambahnya usia, gigi yang paling akhir erupsi lebih rentan terhadap kejadian karies. Hal ini disebabkan karena sulitnya membersihkan gigi yang sedang erupsi. Gigi yang paling akhir erupsi pada gigi sulung adalah gigi geraham. Dilihat dari jenis kelamin, prevalensi karies pada gigi sulung lebih tinggi pada anak perempuan dibanding anak laki-laki. Hal ini disebabkan oleh karena gigi anak perempuan lebih dulu erupsi dibanding gigi anak laki-laki.

Status sosial ekonomi keluarga dapat dilihat dari pendidikan, pekerjaan, pendapatan orang tua. Dari hasil penelitian diketahuitingkat pendidikan orang tua responden termasuk kedalam tingkat pendidikan yang tinggi. Sebagian besar ayah responden yang berpendidikan sarjana sebesar $68,4 \%$ dan ibu responden yang berpendidikan sarjana sebesar $80 \%$. Pendidikan merupakan mempengaruhi status kesehatan seseorang. Seseorang yang memiliki pendidikan tinggi akan memiliki pengetahuan yang lebih baik sehingga sikap dan perilakunya untuk hidup sehat.

Pekerjaan ayah responden sebagai Pegawai Negeri Sipil(PNS) sebanyak 38,5\%. Anak dengan orang tua sebagai PNS mempunyai jaminan kesehatan berupa Asuransi Kesehatan (Askes). Hal ini memperlihatkan biaya kesehatan tidak lagi menjadi masalah dalam keluarganya. Beberapa perusahaan swasta juga melindungi karyawannya dengan asuransi kesehatan. Sebagian besar ibu responden bekerja yaitu sebesar $52,6 \%$. Ibu yang bekerja menyerahkan pola pengasuhan anak kepada pihak lain. Pengetahuan, sikap dan perilaku anak sangat dipengaruhi oleh pengasuhnya. Anak merupakan seorang peniru dan sangat tergantung kepada lingkungan- 
nya. Jika pengasuhnya mempunyai perilaku yang baik terhadap kesehatan maka anak akan mempunyai perilaku yang baik juga terhadap kesehatan.

Status ekonomi responden pada penelitian ini ditentukan oleh pendapatan perkapita orang tua sesuai dengan standar yang dikeluarkan oleh Badan Pusat Statistik. Orang tua responden yang berstatus ekonomi miskin sebesar 24,6\%. Anak-anak dengan orang tua dengan penghasilan cukup, mempunyai kesempatan untuk memperoleh pelayanan kesehatan. Orang tua dengan penghasilan memadai akan memungkinkan memberikan pelayanan kesehatan yang lebih baik kepada anaknya. Orang dengan kemampuan ekonomi kurang akan kesulitan untuk memenuhi kebutuhan pokoknya, sehingga akan sulit memberikan pelayanan kesehatanuntuk keluarganya.

Prevalensi karies akan lebih tinggi pada anak dengan status ekonomi miskin dibanding dengan tidak miskin. Pada penelitian ini sebagian besar responden dengan status ekonomi tidak miskin. Responden dengan status karies baik sebesar 50,9\%. Status karies baik dikatakan jika karies mengenai $\geq 3$ buah gigi. Jika dibandingkan dengan indikator WHO dimana anak umur 5 tahun $90 \%$ bebas karies, sulit akan tercapai. Pada penelitian ini mayoritas responden berumur 5 tahun yaitu 59,7\% dan seluruh responden mempunyai riwayat karies.

Hasil uji statistik memperlihatkan tidak adanya hubungan yang bermakna antara pendapatan orang tua dengan karies yang dialami oleh responden. Pada responden yang miskin, $57,1 \%$ memiliki status karies yang buruk. Pada responden yang tidak miskin, 46,5\% memiliki status karies yang buruk. Dari penelitian ini didapatkan hasil olah data dengan metoda chi-square, dimana nilai $\mathrm{p}=$ $0,490(p>0,05)$, yang artinya tidak ada hubungan yang bermakna dari proporsi status karies responden dengan pendapatan orang tua responden. Karies terjadi disebabkan oleh : host, substrat, mikroorganisme dan waktu. Proses terjadinya karies membutuhkan waktu, mungkin saja karies sudah dialami anak sudah lama sedangkan status sosial ekonominya tidak miskin baru sekarang didapat. Anak-anak mempunyai kebiasaan untuk mengkonsumsi snack dan makanan manis. Snack dan makanan manis dikemas dalam kemasan menarik, dijual dengan harga yang relatif murah dan mudah didapatkan. Penelitian yang dilakukan Holt pada murid prasekolah di Inggris menyatakan bahwa konsumsi makan manis lebih dari empat kali sehari akan meningkatkan kejadian karies.

Hasil penelitian menunjukkan responden dengan ayah yang berpendidikan sarjana 53,5\% memiliki status karies baik sedangkan responden dengan ayah berpendidikan tidak sarjana lebih banyak memiliki status karies buruk yaitu 57,7\%. Responden yang memiliki ibu dengan tingkat pendidikan sarjana memiliki 53,3\% memiliki status karies baik sedangkan responden dengan ibu yang tidak sarjana 58,3\% memiliki status karies buruk. Hal ini menunjukan responden dengan orang tua tingkat pendidikan sarjana lebih banyak memiliki status karies baik dibanding responden dengan orang tua tingkat pendidikan tidak sarjana. Hasil uji statistik menunjukan tidak ada hubungan yang bermakna antara tingkat pendidikan orang tua dengan status karies yang dialami responden. Hal ini bisa disebabkan karena tingkat pendidikan sarjana baru sekarang didapat orang tua responden, 
sedang gigi sulung erupsi lengkap pada usia 2 tahun dan penelitian ini dilakukan pada saat anak usia rata-rata 5 tahun.

Dari hasil penelitian diketahui responden dengan ayah yang bekerja sebagai PNS lebih banyak memiliki status karies baik $(58,6 \%)$ sedangkan responden dengan ayah Non PNS lebih banyak memiliki status karies buruk (60,7\%). Hasil uji statistik menunjukan tidak ada hubungan yang bermakna antara pekerjaan ayah dengan status karies anak. Hal ini mungkin disebabkan karena karies disebabkan oleh multi faktor diantaranya perilaku dalam menjaga kesehatan gigi. Jika keluarga memiliki perilaku yang baik dalam menjaga kesehatan mulut maka anak akan memiliki perilaku yang baik juga.

Dari hasil penelitian diketahui responden dengan ibu yang bekerja memiliki $60 \%$ status karies yang baik sedangkan responden dengan ibu tidak bekerja memilki 59,3\% status karies buruk. Hasil uji statistik menunjukan tidak ada hubungan yang bermakna antara ibu bekerja dengan status karies anak. Ibu yang bekerja akan meningkatkan pendapatan keluarga. Peningkatan pendapatan keluarga akan meningkatkan status ekonomi sehingga memudahkan dalam mendapatkan pendidikan dan pelayanan kesehatan sesuai dengan kebutuhan.

\section{KESIMPULAN DAN SARAN Kesimpulan}

Dari hasil dan pembahasan diatas maka dapat disimpulkan bahwa :

1. Sebagian besar responden berjenis kelamin perempuan.

2. Sebagian besar tingkat pendidikan orang tua responden sarjana.

3. Sebagian besar ayah responden bekerja sebagai Pegawai Negeri Sipil.
4. Sebagian besar ibu responden mempunyai pekerjaan.

5. Sebagian besar responden mempunyai status karies buruk..

6. Terdapat hubungan yang tidak bermakna antara status sosial ekonomi dengan status karies responden.

7. Terdapat hubungan yang tidak bermakna antara tingkat pendidikan orang tua dengan status karies responden.

8. Terdapat hubungan yang tidak bermakna antara pekerjaan orang tua dengan status karies responden.

\section{Saran}

1. Bagi orang tua supaya lebih memperhatikan kesehatan gigi sulung anaknya. Gigi sulung mempunyai fungsi yang sama dengan gigi permanen.

2. Orang tua supaya rutin setiap 6 bulan sekali memeriksakan gigi anaknya ke dokter gigi.

3. Supaya sekolah mengajarkan cara merawat kesehatan gigi dan mulut pada anak-anak di periode gigi sulung.

\section{KEPUSTAKAAN}

1. Suwelo, Ismu Suharsono (1992). "Karies gigi pada anak dengan berbagai faktor etiologi", EGC, Jakarta.

2. Budiharto, 2009, Ilmu Perilaku Kesehatan Dan Pendidikan Kesehatan Gigi, EGC, Jakarta.

3. McDonald, Avery, Dean (2004). Dentistry for the Child and Adolescent, Mosby, St.Louis, Missouri.

4. Moses, Joyson, (2011). "Prevalence Of Dental Caries, Socio-Economic Status And 
Treatment Needs Among 5 To 15 Year Old School Going Children Of Chidambaram", diakses 4 Februari 2012; http://www.jcdr.net/articles/PDF $\underline{11156 / 1435 \text { 1.pdf }}$

5. Riskesdas (2007). "Riset Kesehatan Dasar, Laporan Nasional 2007', http://www.k4health.org/system/ files/laporanNasional\%20Riskes das\%202007.pdf

6. M.H. Hobdell, E,R, Oliveira, R. Bautista, N.G.Mayburgh, R.Lalloo, S.Narendran and N.W. Johnson. "Oral Diseases and socio-economic status (SES)": http://www.ncbi.nlm.nih.gov/pu bmed/12577077.

7. Bhola N., Kumari R., Nidha T., 2008, Utilization of The Health Care DeliverySystem in a District of North India, East African Journal of Public Health, 5 (3): 147-53.

8. Anegundi, Sudha, Bachsin. "Prevalence of dental caries among 5-13-year-old children of Mangalore city",; http://www.utoronto.ca/dentistry /newsresources/evidence_based/ IsCariesInYoungChildrenAnInfe ctiousDisease.pdf

9. A.James, E.David, Brumley,\&U.Jennifer. "Oral diseases and socio-economic status (SES)", British Dental Journal. Vol 194.No 2.203.; http://www.ncbi.nlm.nih.gov/pu bmed/11217596

10. Azwindar, Muhammad. "Hubungan Tingkat Sosial Ekonomi dengan Derajat Kesehatan Gigi dan Mulut Masyarakat Kelurahan Barombong Kecamatan Tamalate Makassar Tahun 2009",; http://chawdnextholmes.blogspo t.com/2010/04/bab-ipendahuluan-1.html

11. Sudigdo, S (2002). "Dasardasar Metode Penelitian Klinis”, Sagung Seto, Jakarta.

12. Notoatmodjo, Soekidjo (2005). Metodologi penelitian kesehatan. Edisi Revisi. Rineka Cipta, Jakarta. 